\title{
Co-creating in Practice: Results and Challenges
}

\author{
Ingrid Mulder $^{1,2}$, Pieter Jan Stappers ${ }^{1}$ \\ ${ }^{I} I D$-StudioLab, Delft University of Technology, Landbergstraat 15, 2628 CE Delft, the Netherlands \\ ${ }^{2}$ Rotterdam University, G.J. de Jonghweg 4-6, 3015 GG Rotterdam, the Netherlands \\ \{i.j.mulder,p.j.stappers\}@tudelft.nl
}

\begin{abstract}
The European Network of Living Labs has been established as one platform for collaborative and co-creative innovation, where users are involved in and contribute to the innovation process. However, what are current practices regarding user-driven open innovation? A review on how existing Living Labs in Europe have implemented the user as co-creator approach across the different stages of product and service innovation showed an emphasis on the $L a b$ part, i.e., a predominant use of traditional methods, but less so on the Living part, i.e., methods of participation and co-creation. In this article, we illustrate how current methods stressing participation and co-creation can be deployed to strengthen current Living lab practices. We conclude with a discussion on the results and challenges to practice cocreation in practice.
\end{abstract}

\section{Keywords}

Co-creation, contextual research, Living Labs, methods, user participation.

\section{Introduction}

Innovation needs continuous investments. Although investments are necessary, their return is not always obvious; only one out of 3000 product ideas makes it on the market, meaning that there are hundreds of unsuccessful ICT products behind every success. Those products that reach the market may sell well but are too often far from user friendly. Surveys show that $75 \%$ of all users find their ICT tools more stressing than relaxing. In such a context, user-centric development and validation can play an important role in speeding up effectively the innovation process through addressing the actual user needs (European Commission, 2009).

Living Labs have been welcomed as the way forward to implement user-driven open innovation. Living Labs are open innovation environments in real-life settings, in which user-driven innovation is fully integrated within the co-creation process of new services, products, and societal infrastructures. The Living Lab concept promises a better understanding in what triggers innovations and which innovations proof to be successful in different environmental, social, and cultural contexts. A Living Lab is not just a network of infrastructure and services; preferably a Living Lab is a living network of real people with rich experiences. It can be said that the core advantage of the Living Lab concept over traditional user-centric methodologies is its multicontextual sphere in which the co-creation of ICT product and service development, and the corresponding evaluation take place (Ballon, Pierson, \& Delaere, 2005). The ability to interact with the users in that space is what distinguishes the Living Lab approach from other crossdisciplinary approaches. Living Lab research can be seen as the place where both fundamental research (Bohr's quadrant; see Stokes, 1997) and pure applied research (Edison's quadrant) meet, it embraces use-inspired innovation research (see Figure 1). This approach thus differs from more classical approaches as users are involved in all stages of the product development lifecycle, not primarily in the testing phase, and that the evaluation emphasises the daily life context. Whereas users are rather seen as a subject in traditional research, in the Living Lab approach users are seen as co-creators of innovation. Differently put, Living Labs - also referred to as flexible ecosystems - can provide a demand-driven 'concurrent innovation' approach by iteratively engaging all key actors across the phases, and putting the user in the driver's seat. 


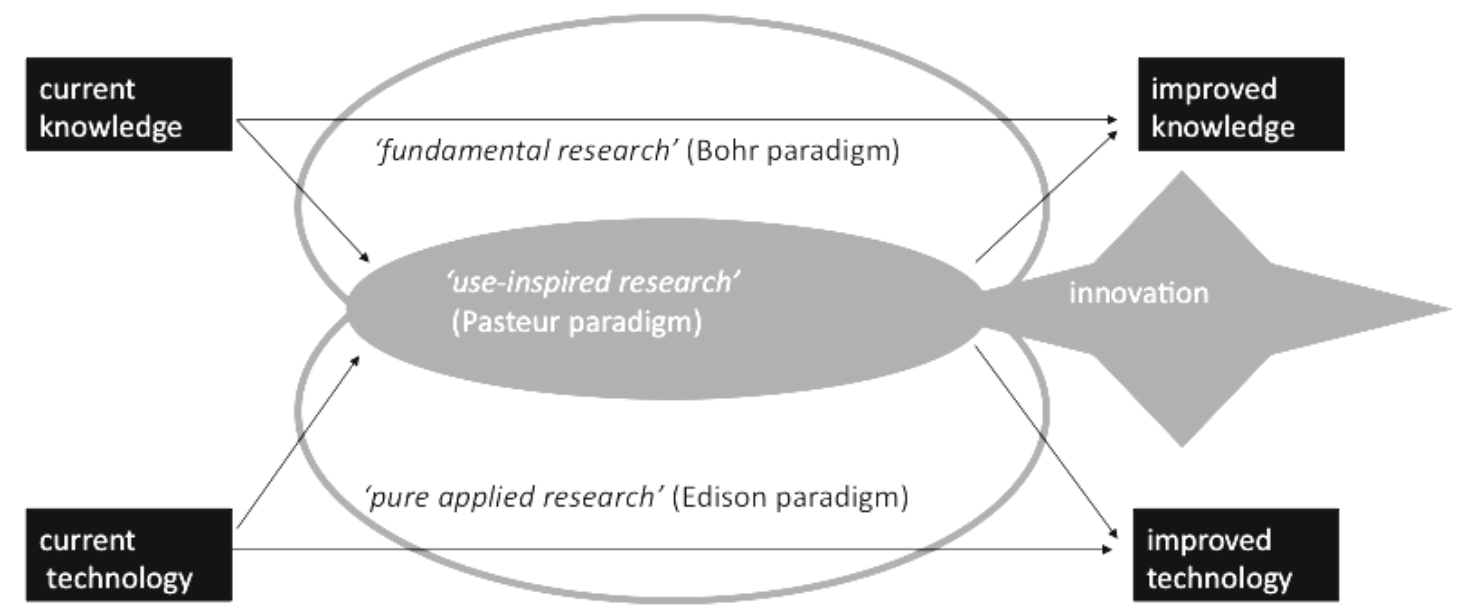

Source: Stokes, 1997

Figure 1: Living Labs as use-inspired research.

In sum, Living Labs are seen as the way forward to stimulate user-driven innovation as they:

- $\quad$ bring the users early into the creative process in order to discover new and emerging behaviours and user patterns;

- bridge the innovation gap between technology development and the uptake of new products and services involving all relevant players of the value network via partnerships between business, citizens, and government;

- allow for early assessment of the socio-economic implications of new technological solutions by demonstrating the validity of innovative services and business models.

Different types of stakeholders involved in user-driven open innovation benefit differently from the Living Lab concept. For users, the benefit might be to be empowered to influence the development of services and products that serve real needs, and to jointly contribute to improved processes through active participation in the product development lifecycles. Participating in a Living Lab makes the innovation process for industry more effective by partnering with other companies as well as end-users, which are rooted in active user experiences, increasing being 'right the first time'. Even for Small \& Medium Enterprises (SMEs), the development, validation, and integration of new ideas and rapidly scaling-up their local services and products to other markets become an opportunity by joining a Living Lab consortium.

For the European Commission Living Labs have a crucial role in keeping the users continuously involved for as their expectations to be monitored and reflected into making better products and services. "An important aspect of the innovation strategy discussed during the i2010 mid-term review is the role played by consumers and end-users as a powerful source of innovation for companies engaging in user-driven open innovation. In particular, the review has addressed the role of the user in the light of the continuously changing landscape of information and communication technologies. As new services and applications are created and taken-up rapidly towards the mass-market scale, it is necessary to ensure that they meet the expectations of the consumers." (European Commission, 2009, p.11).

Concluding, Living Labs open opportunities to get users involved, however, the concept does not explain how to get motivated users involved? In the next section, we elaborate upon current Living Lab practices and how users participated in such user-driven innovation processes. 


\section{Current Living Lab practices}

As said before, the Living Labs concept is a methodology to deal with user-driven open innovation as well as a way to organise the collaborative experimentation and co-creation with real users in a real life environment. The initiative stresses the collaborative nature of modern product and technology development. Collaboration plays a part on two levels. First, between the labs, i.e., mainly across Europe knowledge is shared and compared; second, within each lab, stakeholders in one lab have a connection established with local users user groups, and communities. We will discuss these two types of communication in turn.

\subsection{Co-creative Living Labs}

One of the European Commission FP6 funded projects, called CoreLabs, was in charge to conduct as broad coordination as possible among European private, public, and civic stakeholders towards establishing a coordinated European programme of co-creative Living Labs for a new European research and innovation infrastructure. The overall objective was to initiate a European Network of Living Labs.

So far, over one hundred Living Labs have joined this European Network of Living Labs. This network envisions applying new methodologies for co-creative research and innovation, including new means of developments, IPR, management of research and innovation as well as new forms for direct user involvement in the innovation process. In November 2006, it has been communicated during the launch event of the first wave of Living Labs that a European platform for collaborative and co-creative innovation has been established, where the users are involved in and contribute to the innovation process. This approach should ensure that common methodologies and tools are developed across Europe that support, stimulate and accelerate the innovation process. The European Network of Living Labs has a strong regional growth and development impact by facilitating and fostering regional innovation as interlinked with a European innovation system with a global reach.

Here, too, the CoreLabs project took a coordinating role in specifying and providing a suite of methods and tools which can be applied within the real practice of co-creative Living Labs in order to enhance collaboration within the innovation process not only of the users, but of all stakeholders, be it academia, industry or public bodies. However, practice appears not so straightforward; methods and tools used in Living Labs differ widely. The problem of bridging methods and tools from one Living Lab to another becomes considerably simpler if the two Living Labs in question share the same Living Lab perspective.

For this purpose, the Living Labs Harmonization Cube has been developed (Figure 2). The six sides of the cube correspond with the six dominant Living Lab perspectives, i.e., user involvement, service creation, infrastructure, governance, innovation outcomes, and methods \& tools. Each side of the cube facilitates interoperability between the co-creative Living Labs (see Mulder et al., 2007; Mulder, Velthausz, \& Kriens, 2008a, 2008b for details).

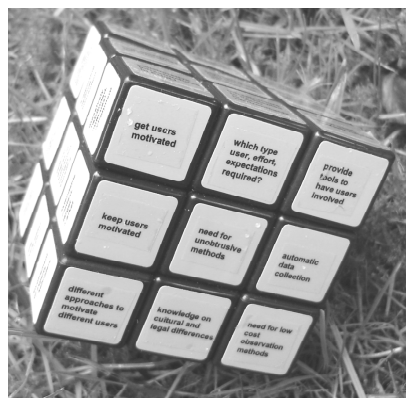

Figure 2: The Harmonization Cube.

The Harmonization Cube is a useful technique that enables the definition of a shared reference of methods and tools. The harmonization cube not only represents the most important perspectives of a Living Lab, it also specifies bridges between existing Living Labs. It helps the different Living Labs to learn from each other, benchmark the validation of user behaviour studies, exchange best practices, and interconnect existing Living Labs. Next to facilitating a common ground for sharing, the cube model recognizes the degree of harmonization of methods and tools used in Living Labs. 


\subsection{Co-creation in Living Labs}

Whereas the previous section referred to co-creation between Living Labs, the current section looks in more detail at co-creation within a Living Lab. Earlier work done in the CoreLabs project (Feurstein, Hesmer, Hribernik, Thoben, \& Schumacher, 2008; Shamsi, 2008) identified current and emerging methods and tools that integrate end-users and other stakeholders in the innovation process of new products and services. A systematic analysis and a comparative study of methods and tools at both the regional sites and at a multi-stakeholder infrastructure level have been made. As the core service of a Living Lab is to facilitate co-creation of a product, service, or application, current and emerging methods and tools have been mapped to the various stages of an innovation process, i.e., product/service idea, product/service concept, product/service development, and market launch (Reichart, 2002, p.117). Each process phase enables co-creation with different methods and tools.

Feurstein and Schumacher (2008) presented an overview of existing Living Labs in Europe regarding how they operate, how they have implemented the user as co-creator approach, regarding the implemented infrastructure as well as the future perspectives of the Living Labs. Regarding the usage of methods across the different stages of product and service innovation, a predominant use of traditional methods was observed in contrast to a rather limited usage of CWE-based methods (see Figure 3). The latter category makes use of capabilities of emerging technologies embedded in Collaborative Work Environments.

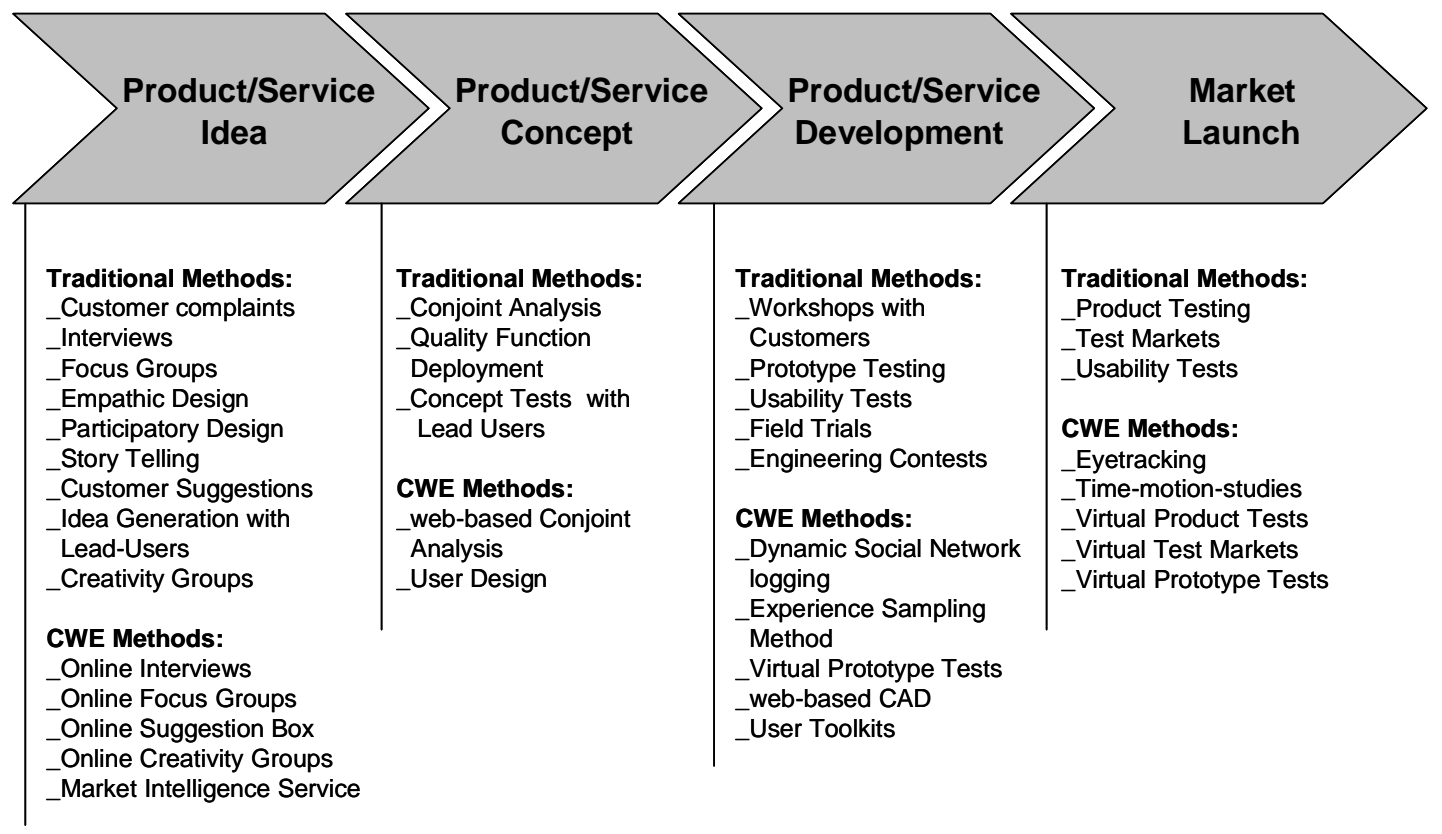

Figure 3: Methods used within existing Living Labs.

About co-creation within Living Labs, it can be said that all Living Labs employed specific methods and tools to interact with their stakeholders across the entire new product and service innovation process. However, mostly, traditional methods have been used within the Living Labs. Traditional methods, of course, have their value in ethnographic research, however, they might not exploit Living Labs as an infrastructure that comes close to the user as well as make use of the potential of Living Labs as a methodology to get richer insights in what drives people. Moreover, methods and tools used are very heterogeneous and are specific to the individual sites (and even vary within each site), making it hard to compare results across the Living Lab sites. All in all, it can be concluded that Living Labs do not currently benefit from the promising Living Lab methodology. In the remainder of this article, we explore how methods and tools for co-creation can be implemented in current Living Lab practices. 


\section{Co-creation is about participation and context}

Main forms of user participation in both industry and academia are still after-the-fact testing. In other words, users can react to a concept prototype in a demonstration, a focus group, or a usability test. The earlier phases in the process are mostly conducted within the lab or company, often based on literature study. This is reflected in the emphasis put on 'demonstrators' as deliverables of projects.

Involving users in earlier phases is important in order to ensure that the concepts of products and services that are developed fit into the lives of the target groups. For that, the development team, including researchers, designers, engineers and other people involved, must build an understanding of the context of product use, i.e., the full ramifications of who, where, what, when, how, and why which surrounds the product. This fuller understanding of the context is the more necessary as current product and service design increasingly address complex interactions between users, products, services, and infrastructure, with increasing opportunities for mistakes due to 'blind spots' in the development team.

Sleeswijk Visser, Stappers, van der Lugt, and Sanders (2005) describe how such information can be gathered from users in a structured way, and point to two important factors: 1) generative activity (having people create artefacts as a way to stimulate observation, reflection, and discussion), and 2) sensitizing (letting participants go through a process of reflection over several days or weeks, in order to deepen their insights. Both tools of expression, and time for reflection are needed to work the participating user into the 'expert of their experience' to contribute with initiative in a living labs process. This goes well beyond current practice of demonstration-andreaction, both in the amount of time and commitment that is invested from all parties as well as in the depth and breadth of results that can be harvested from that.

The term co-creation is hot. But actual long-term or deep involvement of users in product development is limited. In industry, product- and concept-testing (after these have been finalized and implemented) are becoming commonplace. But techniques to involve end-users in the idea generation, information, and strategy-defining phases are not often applied in practice. In part this is because of the enduring technology push, in part because existing methods such as (design) ethnography are expensive and require changes in the way product development processes are conducted in the company. On the other hand, in Europe a range of (mainly academic) projects have shown the viability and value of use-inspired approaches, and have delivered new, appropriate methods. At the same time, especially at large US industries such as Microsoft, new methods have found their way into industrial organizations. Moreover, cocreation techniques are rapidly finding their way into education, and - through the new generation of designers - into practice.

\section{Discussion - Challenges for co-creation}

The core advantage of Living Labs over traditional user-centric methodologies is the contextual space in which the co-creation of ICT product and service development, and its evaluation take place. Besides, the ability to interact with the users in that space distinguishes the Living Lab approach from other cross-disciplinary approaches. The current work showed that most existing Living Labs don't exploit the full potential of a community-driven open innovation approach. Current Living Lab practices largely emphasise the $L a b$ part, i.e., a predominant use of traditional methods for evaluation, rather than the Living part, i.e., methods of participation and co-creation. In the current section, we discuss how current methods stressing participation and co-creation can be deployed to strengthen current Living lab practices. 


\subsection{User as co-creator}

Over the past decades, the distance between designers and users has shrunk again. The by now traditional way is dominated by an 'expert perspective' in which trained researchers observe and/or interview largely passive users. The contribution of the users is to perform instructed tasks and/or to give their opinions about product concepts that were generated earlier by others without any input from them. Figure 4 shows this in the bottom-left corner.

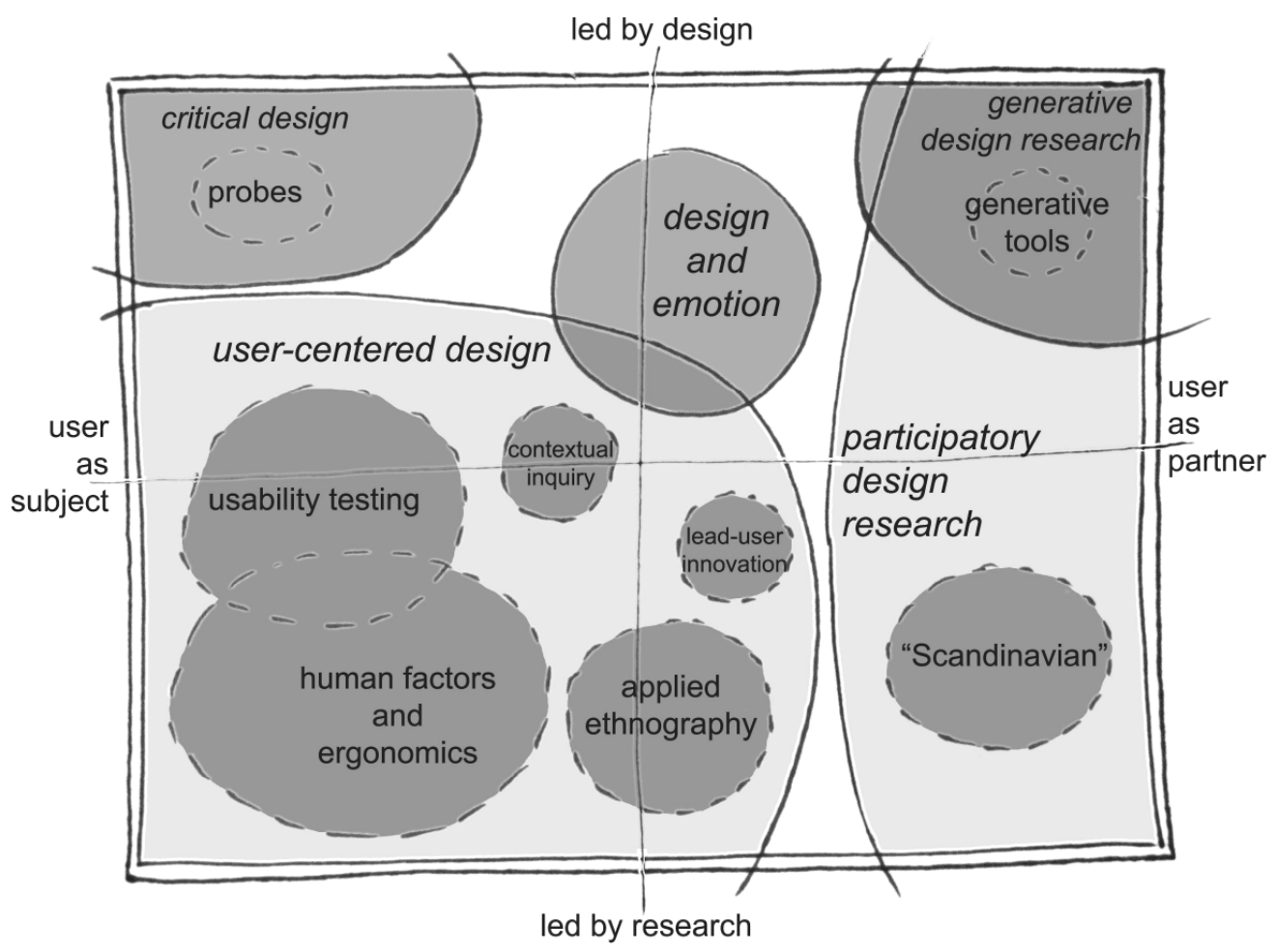

Figure 4: The current landscape of human-centered design research as practiced in the design and development of products and services (from Sanders \& Stappers, 2008).

Increasingly, users appear in roles where they provide expertise and are given room for initiative, by participating in the informing, ideating, and conceptualizing activities in the early design phases. The participatory approach (i.e., 'user as partner', on the right in the diagram) has been led by Northern Europeans. A second dimension of development has been in the type of research that is conducted. The last two decades have shown a growth in research techniques, which have not only evaluative power (prove/disprove a hypothesis or idea), but also generative value (provide insights not yet known to the researchers). These latter developments are often supported by the inclusion of explorative actions using tools and techniques from design, such as making collages, diagrams, models, and other visualizations as a means to support selfobservation and reflection. The two approaches are now beginning to influence one another. Within this landscape, in the area of participatory design, the notions of co-creation and codesign have been growing. As can seen from the human centered design landscape illustrated in Figure 4, the challenge to keep Living Labs living is to involve active users by making use of generative techniques, and so, practicing a 'user as co-creator' approach.

\subsection{Community-driven innovation as the new way of product development}

Theories of innovation (e.g., Scherer, 1982) commonly distinguish two forces: technology push and market pull. If product development relies exclusively on the former, this leads to 'technological tricks in boxes, with a button added to start their use'. The latter, taken alone, caters only to the needs of which people are explicitly aware. The competition on user qualities has created a third force, which can be called the 'contextual push' or the 'people insights push' (Figure 5). 


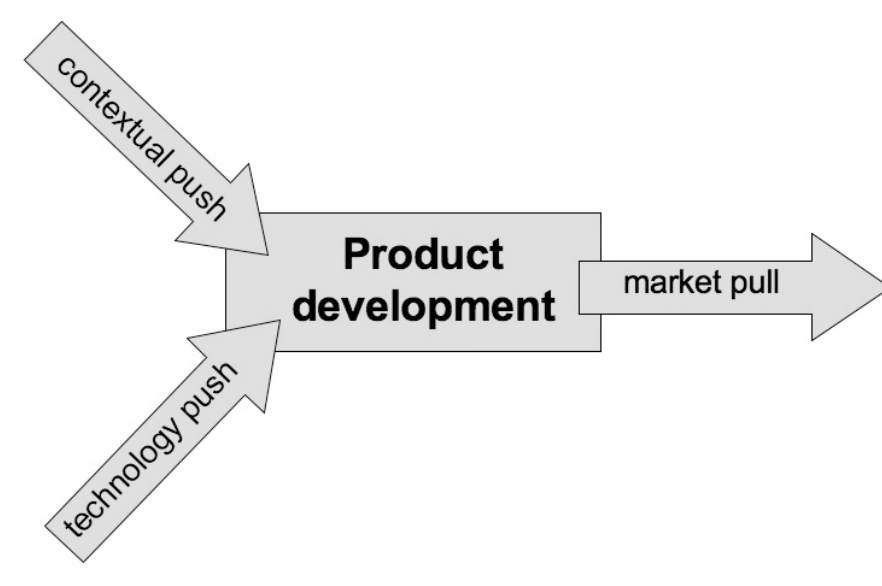

Figure 5: Three forces on new product development (from Stappers et al, 2008).

By this way, new products addressing tacit and latent needs, come about, not through a new technical possibility, or a visible demand from buyers, but through increased insight in the needs and dreams of possible future users. The most telling outcomes of these approaches are new products for which no buyers existed yet, but the approaches can also be applied to existing products and markets.

Key lesson in this area is that everyday people, if involved in an appropriate way (see Sleeswijk Visser et al., 2005), are a rich source of experiential knowledge, and are eager to participate in a design project if their expertise receives appropriate recognition. The participation not only of everyday people as potential customers, but also of all other stakeholders along the value-chain can be seen as the foremost required element for the successful operation of a Living Lab. Cocreation in open innovation requires an open mindset towards sharing and collaboration. This is not trivial. Although board members preach open innovation in pre-competitive collaboration, companies seem not eager to share with competitors. Even within companies, employees are not always keen in sharing ideas.

Participating in a Living Lab is a way to deal with the complexity of product development, which is growing rapidly on many fronts: new technologies, global competition, merging of products, services, and infrastructure, sustainability issues, and speeding up the innovation process. A user as co-creator approach incorporating the user's context helps companies to get deeper insights in the end-users' needs and values.

\subsection{From traditional methods to living methodologies}

The true value of getting deeper insights in user values and needs as well as discovering product or services ideas might be in the fuzzy front end, the early stages of strategy and alliance formation, and concept development. As described in section 2.2 there are many different methods, which can be used to involve the user in the development process of a new service or product. These methods can be divided in more traditional research methods on the one hand, and on the other hand, in ICT enabled methods such as online interviews, web-based conjoint analysis, virtual product testing and user toolkits with make use of the Living Lab infrastructure. In earlier research the four phases of the product/service development process shown in Figure 3 were used to allocate the methods to the phase(s) they are most appropriate for. Although helpful in categorising the Living Lab practices, the model defined by Reichart (2002) starts from existing product/service ideas and consequently does not distinguish the fuzzy front end as a phase in the product development lifecycle.

Whereas the Living Lab approach has been introduced as a methodology for experimentation and co-creation in real life environments, where users together with other stakeholders such as researchers, industry partners, and designers look for new ideas, solutions, new products and services, current Living Labs practices, however, demonstrate reactive users rather than users as 
active co-creators and show insights that are for the most part based on the usage of traditional methods, and are consequently, not exemplary in demonstrating the added value of a Living Lab over traditional user-centric methodologies. In order to have the Living Lab methodology growing to maturity, it is crucial to awake the living part by making us of its infrastructure, and by continuously evaluating in all phases, thus during use and in-situ. In addition, the use of living methodologies (Mulder et al, 2008a) to come close to the user and his rich experiences as well as giving attention to the fuzzy front end as a phase advancing the product/service idea might be promising. Invaluable insights by co-creation for the development process might be deciphered just in this early phase. Living methodologies such as generative tools and contextmapping techniques (Sleeswijk Visser et al., 2005) proved to be successful for that as well. Moreover, by capturing rich experiences and social dynamics of everyday life, Living Labs make far better use of the promised ecological validity of this community-driven innovation approach.

\section{Acknowledgement}

This work has been mainly based on the authors' experiences in both the CoreLabs project and the Contextmapping project. The IST Project CoreLabs: Co-creative Living Labs (No. IST-035065) has been partly funded by the European Commission (www.corelabs.eu). The Contextmapping project has been conducted within ID-StudioLab, a research though design community of the Delft University of Technology. Special thanks go from the authors to all that joined us in these projects for their active role in co-creation and idea generation. We thank Froukje Sleeswijk Visser in particular for her constructive feedback in shaping the current article.

\section{References}

Ballon, P., Pierson, J., \& Delaere, S. (2005). Test and Experimentation Platforms For Broadband Innovation: Examining European Practice. In: Conference Proceedings of 16th European Regional Conference, International Telecommunications Society (ITS), Porto, Portugal, 4-6 September, 2005.

European Commission (2009). Living Labs for user-driven open innovation, an overview of the Living Labs methodology, activities and achievements, January 2009.

Feurstein, K., Hesmer, A., Hribernik, K.A., Thoben, K.-D., \& Schumacher, J. (2008). Living Labs: A New Development Strategy. In: Schumacher, J. \& Niitano, V-P. (eds.). European Living Labs - a new approach for human centric regional innovation (pp. 1-14). Berlin: Wissenschaftlicher Verlag Berlin.

Feurstein, K. \& Schumacher, J. (2008). Best Practice Report. CoreLabs deliverable D2.1b. www.corelabs.eu.

Mulder, I., Fahy, C., Hribernik, K., Velthausz, D., Feurstein, K., Garcia, M., Schaffers, H., Mirijamdotter, A., \& Stahlbrost, A. (2007). Towards harmonized methods and tools for Living Labs. In: P. Cunningham \& M. Cunningham (eds.). Expanding the Knowledge Economy: Issues, Applications, Case Studies (pp. 722-729), IOP Press.

Mulder, I., Velthausz, D., \& Kriens, M. (2008a). Living Methodologies: Understanding the Dynamics of Innovation. In: Schumacher, J. \& Niitano, V-P. (eds.). European Living Labs - a new approach for human centric regional innovation (pp. 31-38). Berlin: Wissenschaftlicher Verlag Berlin.

Mulder, I., Velthausz, D., \& Kriens, M. (2008b). The Living Labs Harmonization Cube: Communicating Living Lab's Essentials. Ejov, The Electronic Journal for Virtual Organizations and Networks. Vol. 10, Executive.

Reichart, S.V. (2002). Die Gestaltung des Produktinnovationsprozesses, In: Reichart, M. (Hrsg.), Prozessmanagement mit System (pp. 97-132). Wissenschaftlicher Verlag, Berlin, Germany.

Sanders, E.B.-N. \& Stappers, P.J. (2008). Co-creation and the new landscapes of design. CoDesign, 4(1), 5-18.

Scherer, F. M. (1982). Demand-pull and Technological Opportunity: Scmookler Revisited. Journal of Industrial Economics, 30, 225-37.

Shamsi, T.A. (2008). Living Labs: Good Practices in Europe. In: Schumacher, J. \& Niitano, V-P. (eds.). European Living Labs - a new approach for human centric regional innovation (pp. 15-30). Berlin: Wissenschaftlicher Verlag Berlin.

Sleeswijk Visser, F., Stappers, P.J., van der Lugt, R. \& Sanders, E.B.-N. (2005). Contextmapping: Experiences from practice. CoDesign: International Journal of CoCreation in Design and Arts, 1(2), 119-149.

Stappers, P.J., van Rijn, H., Kistemaker, S., Hennink, A., Sleeswijk Visser, F. (2008) Designing for other people's strengths and motivations. Advanced Engineering Informatics, 23, 174-183.

Stokes, D.E. (1997). Pasteur's Quadrant - Basic Science and Technological Innovation. Washington D.C.: Brookings Institution Press. 